\title{
Fighting TB requires empowered patients
}

In this article from India, Deepti Chavan describes the differences in health outcomes when patients are able to access the information they need

\section{Deepti Chavan}

I was 16 when I first started coughing. It was in the middle of school exams. After months of coughing non-stop, I had a chest $\mathrm{x}$ ray and it was confirmed. "You have TB," my general practitioner said. These three words changed my life. I didn't know anything about this disease. I was about to start university. Everything changed. From a young person filled with hope I became an anxious patient.

\section{No information}

I went to one doctor after another. At first I went where I was referred. Later I undertook my own search for a doctor who would be able to help. They did not tell me about the disease or its progression. I felt I just had to trust them-like God; you never see her but you have to believe. Everyone promised a cure and would experiment with my medication, but I didn't get better. No one told me about the horrific side effects; nobody directed me to any resources that would help. I felt lost, angry, and helpless. After a year my doctor told me that I had multidrug resistant TB and required surgery.

My family and I had no clue what that meant and no other options were discussed. A decade later I wonder why no doctor ever advised me to get a drug susceptibility test earlier, instead of just changing medicines.

Post-surgery I had to continue with medicines and injections, but my condition deteriorated. Desperate, I started surfing the net to find a doctor who could help me. Three years after my first diagnosis, I found one in the UK who referred me to a specialist in Mumbai.

\section{Treatment beyond drugs or surgery}

Under this new doctor's care I realised for the first time that a patient could ask questions, and could frankly share their apprehensions. I was used to doctors rejecting what I said; when I told them that I was suffering from a side effect, they just dismissed it saying that nothing of that sort happens, that it was just in my mind. Because of this I became hesitant to voice my concerns to any doctor because I knew I would get the same answer.

But with the new doctor it was different. He told me that he understood how difficult it is to consume so many medications and that I was being very brave. He explained to me that my case was difficult, but he motivated me at the same time, reassuring me that I could fight it.

When a doctor says that he has faith in his patients and understands their struggle it gives them confidence; it is part of good treatment.

By now my health had become much worse and I required further surgery, which was potentially life threatening. Eventually I found a surgeon who, although he believed I would most likely die on the operating table, was willing to try. In fact, I was out of the intensive care unit the next day-faith, miracles, who knows?

\section{Survivors do wonder}

Today I am cured of TB but it took six years of medicines, 400 injections, and two major surgeries.

TB is as much a mental fight as it is a physical one. As the doctor you are my most trustworthy ally and you need to know that until you empower me I will either give up this fight or lose. You need to listen to me when I say a medicine isn't working or that I am experiencing side effects. If I have a disease like TB or HIV, you need to test me for drug resistance up front, not change medicines without offering a good reason. Perhaps if my doctors had done the test earlier, my lung could have been saved.

Competing interests: I have read and understood BMJ policy on declaration of interests and declare the following: none.

Published by the BMJ Publishing Group Limited. For permission to use (where not already granted under a licence) please go to http:/group.bmj.com/group/rights-licensing/ permissions 


\section{What you need to know}

- Help patients and their families understand the detail of what might happen in the course of their disease, including medication side effects

- Don't change treatments without a clearly explained reason

- Patients need information, empathy, and encouragement as well as drugs

\section{Notes for international readers}

Deepti Chavan was mainly treated in private practice, starting with a doctor in a primary care clinic, but was advised to seek a second opinion from a doctor in the public sector before surgery took place 